\title{
THE IMPACT OF GENETIC ALGORITHM PARAMETERS ON THE OPTIMIZATION OF HYDRO-THERMAL COORDINATION
}

\author{
${ }^{1}$ Tomáš KINCZER, ${ }^{2}$ Peter ŠULEK \\ Department of Hydraulic Engineering, Faculty of Civil Engineering, \\ Slovak University of Technology in Bratislava, Radlinského 11, 810 05, Bratislava, Slovakia, \\ e-mail: ${ }^{1}$ tomas.kinczer@stuba.sk, ${ }^{2}$ peter.sulek@stuba.sk
}

Received 18 December 2015; accepted 4 May 2016

\begin{abstract}
Nowadays heuristic methods are one of the most used tools for the optimization of problems. The proof of that is the fact that they are widely used in chemistry, economics and energy. Among the most popular of heuristic methods belong the genetic algorithms. They can handle difficult, large-scale problems with many parameters, like the optimization of the hydrothermal coordination of hydro and thermal power plants. As with any other method, genetic algorithms also have certain parameters. These parameters, among others, are the size of the population, the maximum number of generations, and the probability of crossovers and mutations. The effect of these parameters on the results of an optimization using genetic algorithms is the focus of this paper. The hydro-thermal coordination of one hydro and one thermal power plant was used as an example to explain this issue.
\end{abstract}

Keywords: Sensitivity analysis, Genetic algorithms, Optimization, Hydro power plant

\section{Introduction}

Most Hydro Power Plants (HPP) transmit the electricity they produce into a uniform system called a Hydro-Thermal System (HTS) [1], [2], [3] and [4]. This system also includes Thermal Power Plants (TPP), which transmit the electricity they produce. When planning the production of electricity, it is important for every element to have the same objective, which is defined by common criteria for the optimization of the whole system. This is called Hydro-Thermal Coordination (HTC). HTC is a complicated optimization problem. To solve this problem, optimal control methods are often used. Nowadays in addition to the classic numerical methods, like linear/non- 
linear programming, modern heuristic methods are more frequently used. The function that describes an HTC problem has a complicated shape of the surface and many local extremes. When solving simpler problems, numerical methods show a high degree of efficiency, but they often tend to have difficulty solving complex problems and can encounter a so-called 'curse of the size of the problem'. For complex problems, similar to HTC, which is marked as a large-scale problem, it is better and more suitable to use heuristic methods. One of the most important heuristic methods is the Genetic Algorithms (GA). They are based on Darwin's principle of the survival of the fittest. They use algorithmic models and mechanics that follow natural selection, thereby mimicking the laws of nature. These mechanics ensure that every next generation should be better than the previous one. In the case of GAs these mechanics are selection, crossover and mutation. They provide a gradual approximation of the best solution of the problem. The optimal solution itself is the best individual (chromosome) from a set of solutions. In other words, GAs select, crossover and mutate generations of a solution to create new and better generations. A GA evaluates each generation using a fitness value. This value represents the chromosome's quality; every chromosome has it, and it is unique to it. Chromosomes with a small degree of fitness are 'extinct'; those with a high degree of fitness are passed on to the next generation. This process gradually gets the GA closer to the best solution. A more detailed description of this process is available in [5]. Other examples of GAs solving an HTC problem can be found in [6]-[12] and [13]. GAs also has disadvantages. High risk of getting stuck in a local extreme and a complicated definition of the penalization functions are some of them. Unlike numerical methods like the Simplex method (which is characterized by its straightforward solution of a problem), solutions found by GAs are often dependent on the correct setting of the parameters of the GAs. The basic parameters of GAs are:

- $\quad N_{p}$ - size of the population. The number of chromosomes in one generation. Generation zero, with which a GA starts, is generated randomly and represents the first solution to a problem;

- $\quad N_{g}$ - maximum number of generations. That is the number of generations over which the population evolves. The number of chromosomes in every generation is the same;

- $\quad P_{\text {cross }}$ - probability of crossover. The value of the $P_{\text {cross }}$ represents the percentage of the probability of a crossover to happen. Crossovers are exchanges of genes between chromosomes. The result is the same amount of chromosomes as before the crossover, but with new genes. The recommended value in the literature is 0.75 ;

- $\quad P_{m u t}$ - is the probability of mutation. In most cases there is a very small probability of a gene or genes mutating into another gene or genes. The recommended value is from 0.05 to 0.10 .

In the following section the paper will focus on the impact of parameter settings on the solution of an HTC problem solved by GAs. As an example, models of one hydro power plant (HPP Zilina) and one thermal (coal) power plant (TPP Novaky) were used. 


\section{Basics and methods}

\subsection{Description of the HTC problem}

A criterion for the optimal solution of an HTC is achieving minimal production and distribution costs, while following all the restrictions that the system has. This criterion is called a regime economy and ensures an optimal solution for distributing an electricity load between electricity producers (which in this case is the above-mentioned model of 1 HPP and 1 TPP). The optimization is planned for the next 24 hours (the socalled D+1 plan) and can be described in terms of the Peak Shaving (PS) method by function (1):

$$
F=\sum_{i=1}^{24} P(T E+V E)_{i} \cdot Q_{V E i} \rightarrow \max ,
$$

where $i$ is the index of the time step of the solution (hour); $P_{(T E+V E) i}$ is the overall production requested of the HTS in $i$-hour in [MW]; the variable the GAs are searching for is $Q_{V E i}$, which is the discharge flowing through HPP Zilina during an $i$-hour in $\left[\mathrm{m}^{3} \cdot \mathrm{s}^{-1}\right]$. It is necessary to note that a linear form of the equation was chosen to be able to compare the results of GAs with the Simplex method. The Simplex method was chosen because of its ability to always find the global extreme of a given problem. Peak shaving methods according to [14], [15] and [16] are based on the assumption that electricity production at an HPP should cover peak sections of an electricity load and that the rest should be covered by a TPP. A solution using the peak shaving method assumes that the configuration of blocks in a TPP are constant during the planning period along with the characteristics of the running costs.

\subsection{Optimization model of the hydro and thermal power plant}

The goal of the HTS is to plan the distribution of the load between HPP Zilina and TPP Novaky to achieve the lowest fuel costs possible. The set of inputs for the HTS model includes prediction of peak loads of daily electricity load (Table I), prediction of inflow into reservoir (Table II) and data based on the manipulation orders of the HPP and on the actual operations.

Table I

Prediction of peak loads of daily electricity load - $P_{(T E+V E) i}$

\begin{tabular}{|l|l|l|l|l|l|l|l|}
\hline Hour & $\begin{array}{l}\text { Load } \\
{[\mathrm{MW}]}\end{array}$ & Hour & $\begin{array}{l}\text { Load } \\
{[\mathrm{MW}]}\end{array}$ & Hour & $\begin{array}{l}\text { Load } \\
{[\mathrm{MW}]}\end{array}$ & Hour & $\begin{array}{l}\text { Load } \\
{[\mathrm{MW}]}\end{array}$ \\
\hline 1 & 114 & 7 & 113 & 13 & 136 & 19 & 138 \\
2 & 114 & 8 & 119 & 14 & 134 & 20 & 133 \\
3 & 114 & 9 & 125 & 15 & 131 & 21 & 130 \\
4 & 113 & 10 & 130 & 16 & 132 & 22 & 124 \\
5 & 114 & 11 & 136 & 17 & 138 & 23 & 120 \\
6 & 113 & 12 & 138 & 18 & 140 & 24 & 114 \\
\hline
\end{tabular}


Table II

Prediction of the inflow into the reservoir from the Vah and the Vavrinka rivers

\begin{tabular}{|c|c|c|c|c|c|c|c|}
\hline Hour & $\begin{array}{c}\text { Inflow } \\
{\left[\mathrm{m}^{3} \cdot \mathrm{s}^{-1}\right]}\end{array}$ & Hour & $\begin{array}{c}\text { Inflow } \\
{\left[\mathrm{m}^{3} \cdot \mathrm{s}^{-1}\right]}\end{array}$ & Hour & $\begin{array}{c}\text { Inflow } \\
{\left[\mathrm{m}^{3} \cdot \mathrm{s}^{-1}\right]}\end{array}$ & Hour & $\begin{array}{c}\text { Inflow } \\
{\left[\mathrm{m}^{3} \cdot \mathrm{s}^{-1}\right]}\end{array}$ \\
\hline 1 & 65 & 7 & 70 & 13 & 70 & 19 & 80 \\
2 & 65 & 8 & 70 & 14 & 70 & 20 & 70 \\
3 & 65 & 9 & 70 & 15 & 65 & 21 & 65 \\
4 & 70 & 10 & 70 & 16 & 75 & 22 & 65 \\
5 & 75 & 11 & 70 & 17 & 90 & 23 & 60 \\
6 & 75 & 12 & 70 & 18 & 90 & 24 & 60 \\
\hline
\end{tabular}

The parameters of TPP Novaky (which represents a thermal system) that are important for this model are the regulatory scope of the TPP ranging from $P_{\text {TEmin }}=50 \mathrm{MW}$ to $P_{\text {TEmax }}=440 \mathrm{MW}$ and the characteristics of the running costs represented by equation $N=0.0132 P_{T E}^{2}+1.024 P_{T E}+1456 € /$ hour. In the case of a TPP covering the whole predicted load itself, the running costs would be 43,053.0 €/day.

The parameters of HPP Zilina (which represents a hydro system) that are important for this optimization are two Kaplan type turbines with a regulatory scope ranging from $P_{\text {TEmin }}=50 \mathrm{MW}$ to $P_{\text {TEmax }}=440 \mathrm{MW}$; the discharge capacity of each turbine is in a range from $Q_{T G m i n}=50 \mathrm{~m}^{3} \cdot \mathrm{s}^{-1}$ to $Q_{T G \max }=150 \mathrm{~m}^{3} \cdot \mathrm{s}^{-1}$; the reservoir above HPP Zilina has a maximum volume of water $V_{Z \max }=3.918 \mathrm{mil} . \mathrm{m}^{3}$ and a minimum volume of $V_{Z \min }=0 \mathrm{~m}^{3}$. At the beginning of the planning period the volume was $V_{Z i n}=2,766 \mathrm{mil} . \mathrm{m}^{3}$, which is the same volume required to have in the reservoir at the end of the planning period (day) $V_{Z i n}=V_{Z f i n}$. The fish ladder at HPP Zilina needs a constant feed of $2.5 \mathrm{~m}^{3} . \mathrm{s}^{-1}$.

The solution to the Hydro-Thermal Coordination (HTC) problem is represented by vector $\mathbf{s}=\left(Q_{V E 1, \ldots, Q_{V E 24}}\right)$. The values of the elements of the vector $\mathbf{s}$ (i.e., the operating plan of HPP Zilina in a one-hour range) are the result of the maximization of the function (1), which must be modified by constraining conditions (2)-(4), which are based on the constraints defined in the handling regulations of HPP Zilina:

$$
\begin{aligned}
& 0 \mathrm{~m}^{3} \cdot \mathrm{s}^{-1} \leq Q_{V E i} \leq 300 \mathrm{~m}^{3} \cdot \mathbf{s}^{-1}, \\
& 0 \mathrm{~m}^{3} \leq V_{Z i} \leq 3918000 \mathrm{~m}^{3}, \\
& V_{Z 0}=V_{Z i n}=V_{Z f i n}=2766000 \mathrm{~m}^{3} .
\end{aligned}
$$

\subsection{Using a $G A$}

GAs in general solve unconstrained optimization problems by following block scheme shown in Fig. 1. It is necessary to modify function (1) in order to use it for solving the HTC problem into a constrained form. This was achieved using penalization functions. Function (1), which represents the fitness values, is modified into a pseudofitness function with the following constraints (5), 


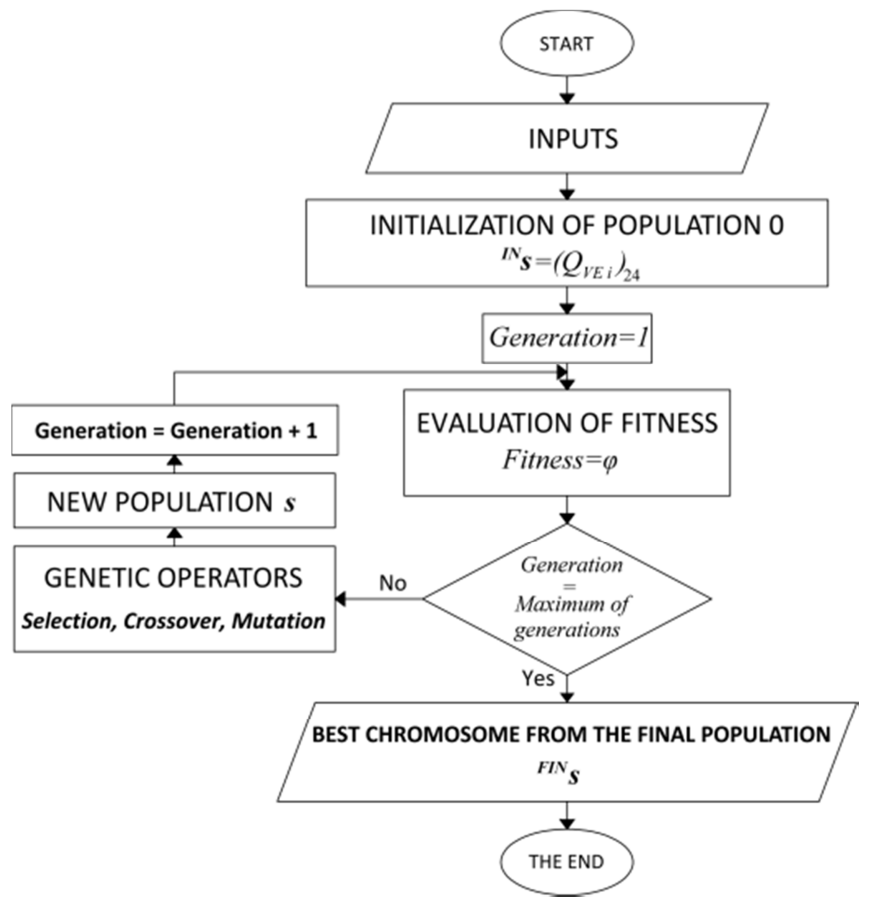

Fig. 1. Block scheme of the optimization model

$$
\begin{aligned}
& \varphi=\sum_{i=1}^{24} \operatorname{Dem}_{i} Q_{H P, i}-W_{\text {pen }}\left(s_{1} \frac{\text { pen }_{1}()}{\max \left(\text { pen }_{1}()\right)}+s_{2} \frac{\text { pen }_{2}()}{\max \left(\text { pen }_{2}()\right)}\right) \rightarrow \max , \\
& \operatorname{pen}_{1}\left(V_{i}, 0\right)= \begin{cases}\sum_{i=1}^{N_{1}}\left(0-V_{i}\right)^{2}, & V_{i}<0, \\
0, & V_{i} \geq 0,\end{cases} \\
& \operatorname{pen}_{2}\left(V_{24}, 2766000\right)= \begin{cases}\sum_{2}^{N_{2}}\left(V_{24}-2766000\right)^{2}, & V_{i}<2766000, \\
i=1 & V_{i} \geq 2766000, \\
0, & \end{cases}
\end{aligned}
$$

where pen $_{1,2}$ are the penalization functions representing restrictions (3) and (4); $W_{\text {pen }}$ is the penalty weighting factor, and $s_{1,2}$ describes how strictly the restrictions will be followed. By means of the mutual proportion of the individual factors, it is possible to 'tighten' or 'loosen' the individual limits of the task. Constraint (2), i.e. the limits of variable $Q_{V E i}$, is set as the upper and lower boundaries of the interval from which the GA can select the elements of solution vector $\mathbf{s}$ - the individual genes. If there is the assumption, that the strictness of observing the boundaries is the same for all the constraints $s_{1}=s_{2}=1$, the value of penalty factor $W_{p e n}$ has a significant impact on the 
process of the selection of the best individual. The setting of $W_{\text {pen }}$ is a complex problem, and its value should be set so that the pseudo-fitness value will never exceed the global maxima $F_{\text {max }}$. Therefore, every solution that violates the constraints should be penalized in a way that it will be worse than a solution that follows all the constrictions. On the other hand, too big a $W_{p e n}$ can cause a premature convergence to a solution. Fig. 2 evaluates typical pseudo-fitness functions using GAs for the 3 values of $W_{\text {pen }}=10^{9}, 10^{10}$ and $10^{11}$. Fig. 3 and Fig. 4 show the evaluation of GA that fallowed or violated restriction constrains (2)-(4). The solution was allowed to develop in a population of 5000 individuals in 1000 generations. The probability of crossover was set to $P_{\text {cross }}=0.75$ and the probability of a mutation to $P_{m u t}=0.02$ (according to recommendations from the literature). The solution with $W_{p e n}$ set to the value $W_{p e n}=10^{11}$ was the one converging to a false solution. The best solution calculated with the Simplex method is $F_{\max }=233052$. Using $W_{p e n}=10^{9}$ the GA achieved a result of 233750 . This pseudo-fitness value exceeds the value from the Simplex method; therefore it is a false solution because it violated volume constraint $V_{z 24} \geq 2.766 \mathrm{mil} . \mathrm{m}^{3}$. The closest to the best solution were the GAs using $W_{p e n}=10^{10}$.

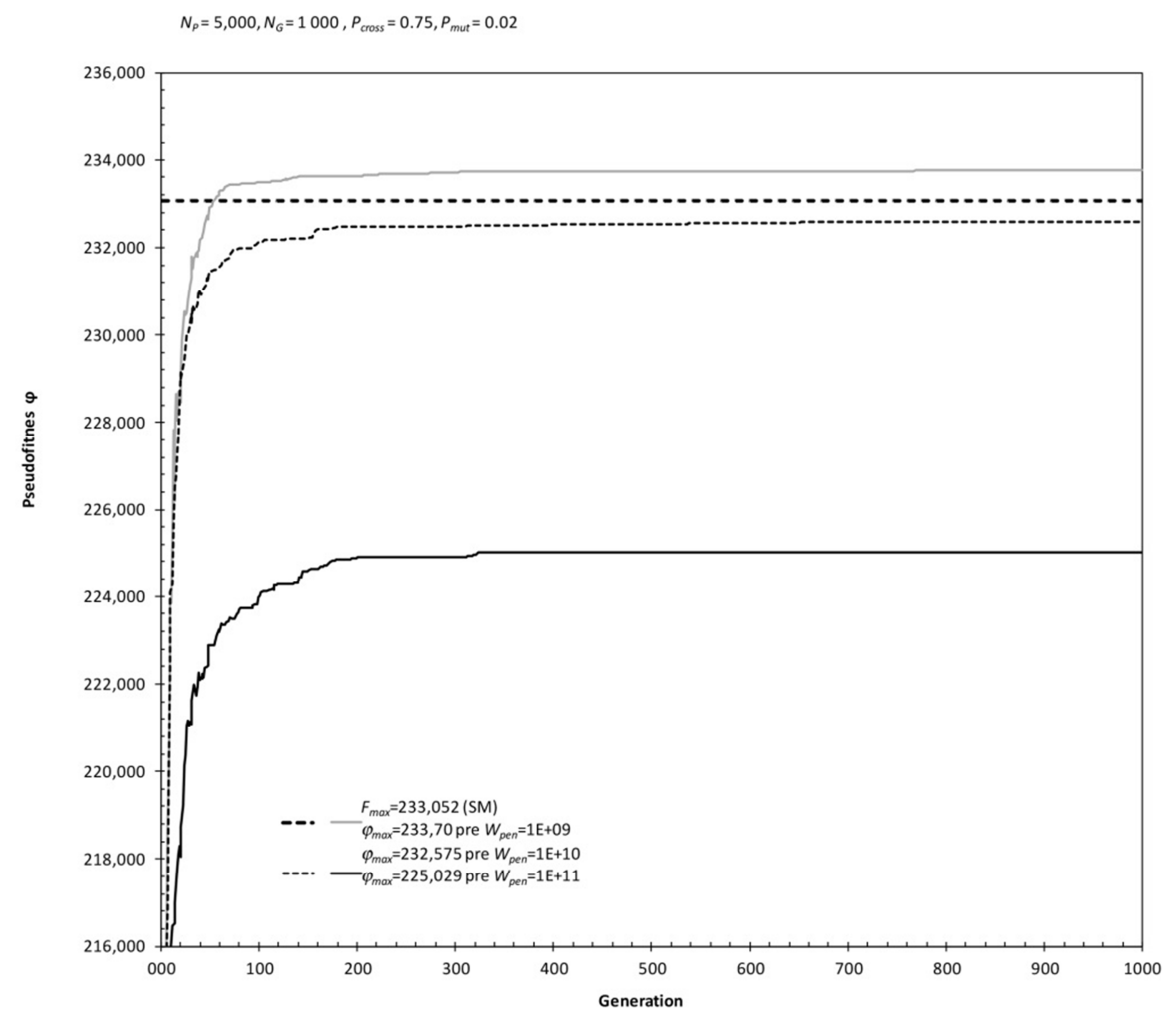

Fig. 2. Gradual approximation of GA to solution (including one false solution) 


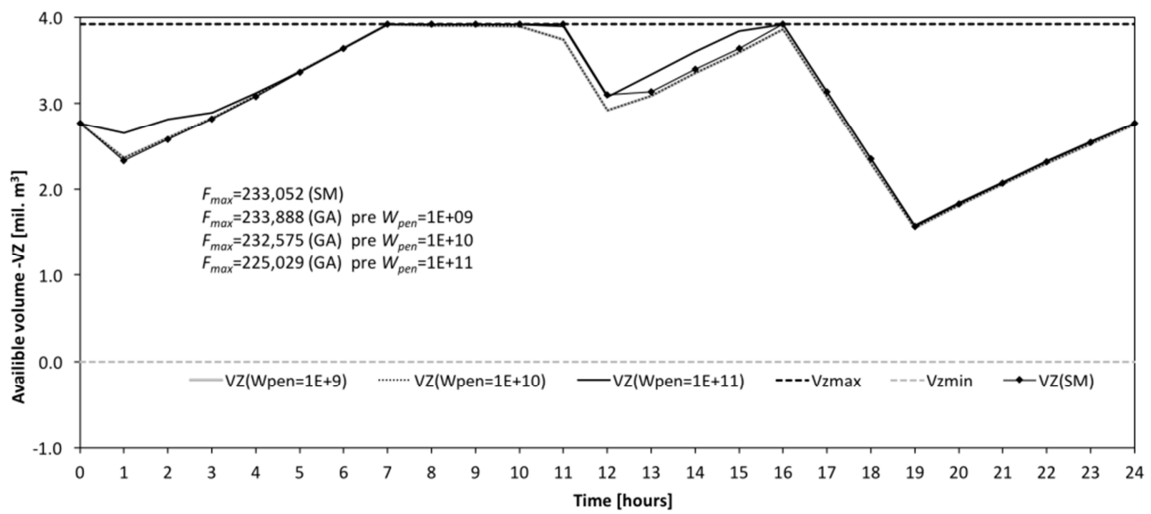

Fig. 3. Development of volume in reservoir during optimization - evaluation of restriction constrains (3) and (4)

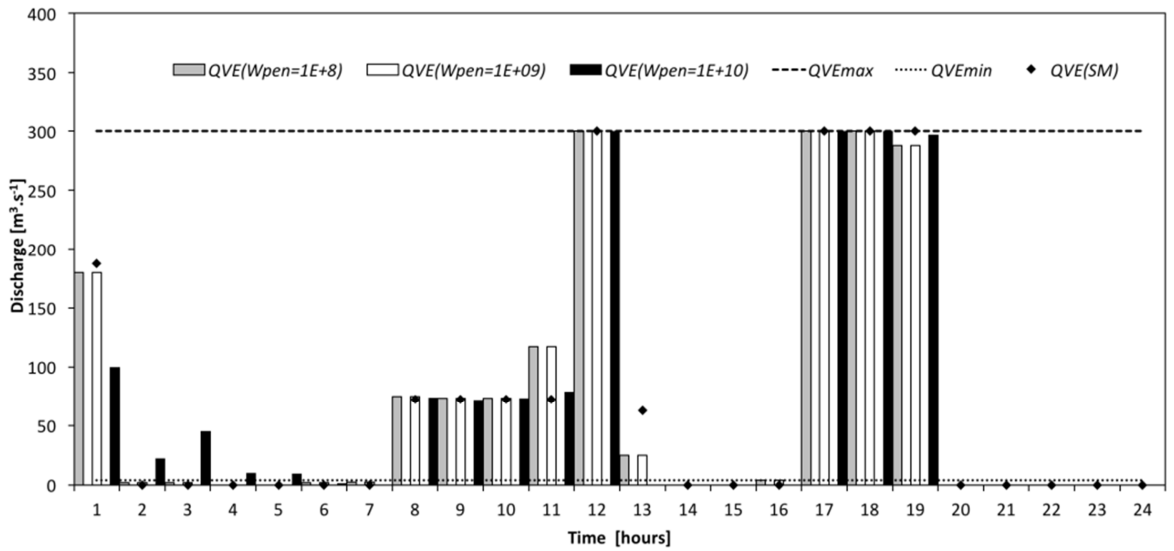

Fig. 4. Discharge through the turbines of HPP during 24 hour plan - evaluation of restriction constrain (2)

The model used for the optimization was based on the results achieved and the above-mentioned equations. The model of the hydro-thermal system consisting of 1 HPP (Zilina) and 1 TPP (Novaky) was modelled using Visual Basic 6 programming language with an integrated .dll library, which is a part of the Genetic Server made by Neuro Dimensions System, Inc [17]. The result of the maximization of function (1) and the solution to the HTC problem is the best individual from the final population of individuals represented by vector ${ }^{F I N} \mathbf{S}=\left(Q_{V E i}\right)_{24}$. A sensitivity analysis of the impact of population size $N_{p}$, crossover probability $P_{c r o s s}$, and mutation probability $P_{m u t}$ was made using the optimization model. 


\section{Results of $t$ sensitivity analysis}

\subsection{Influence of population size $N_{p}$}

In Fig. 5 and Fig. 6 the results of the sensitivity analysis of the effect of the population size on the maximization of the pseudo-fitness function using GAs can be seen. The values shown represent 50 simulations of the GA for each setting of $N_{p}$. Simulations that violated any of the constraints were not included. Satisfactory results were achieved with $N_{p}=2000$ and higher (Fig. 5) in the $1000^{\text {th }}$ generation (Fig. 6). The results are not better with more generations; only the time needed for the calculation is extended.

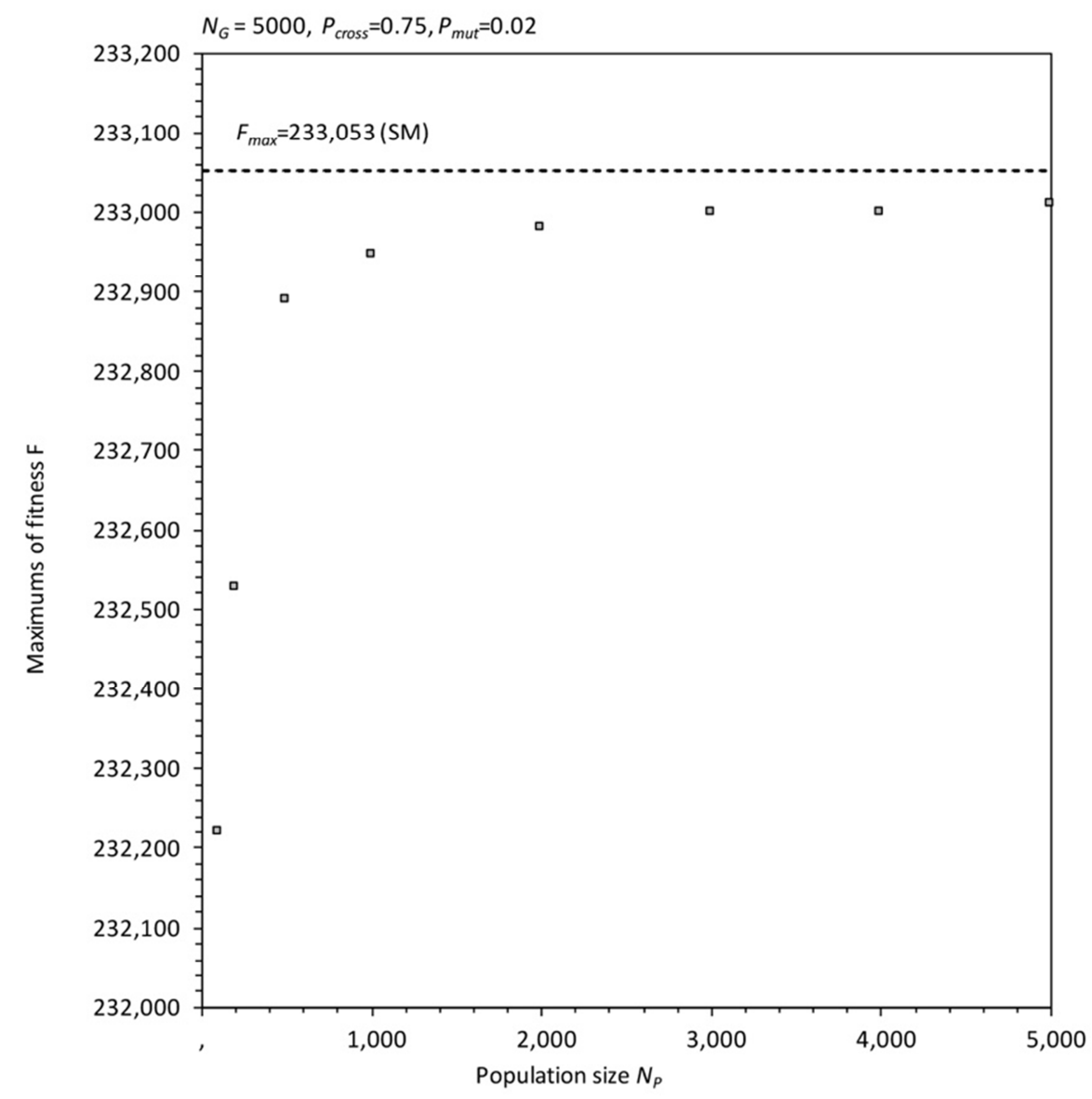

Fig. 5. Effect of population size $N_{p}$ on result 


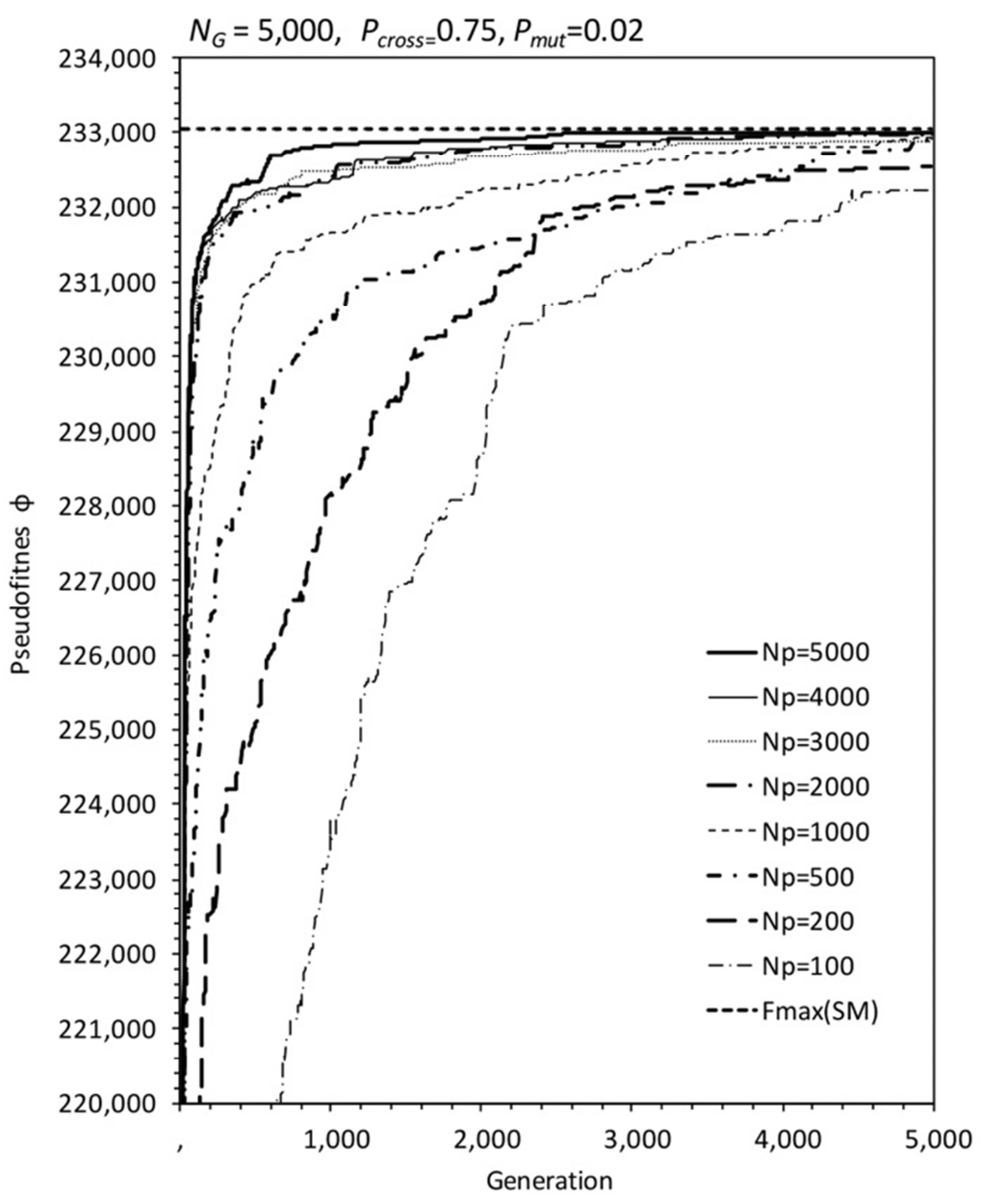

Fig. 6. Development of solution for individual population sizes

\subsection{Effect of the mutation probability $P_{\text {mut }}$ and crossover probability $P_{\text {cross }}$}

The effect of these two probabilities can be seen in Fig. 7. The values were achieved by averaging 50 simulations of the GAs for every combination of $P_{\text {cross }}$ and $P_{\text {mut }}$. The simulations that violated any restriction were excluded. It is clear from the results that $P_{m u t}$ has a more significant effect on the results than $P_{\text {cross }}$. The effect of $P_{\text {cross }}$ was not actually proven. According to many authors, the crossover operator is often subject to opposing opinions, as well as whether it should be used at all, since for some members of academia, it bears a certain undertone of sexuality. The opponents of the crossover operator argue that it breaks promising individuals and should be used with such a small probability as mutation. 


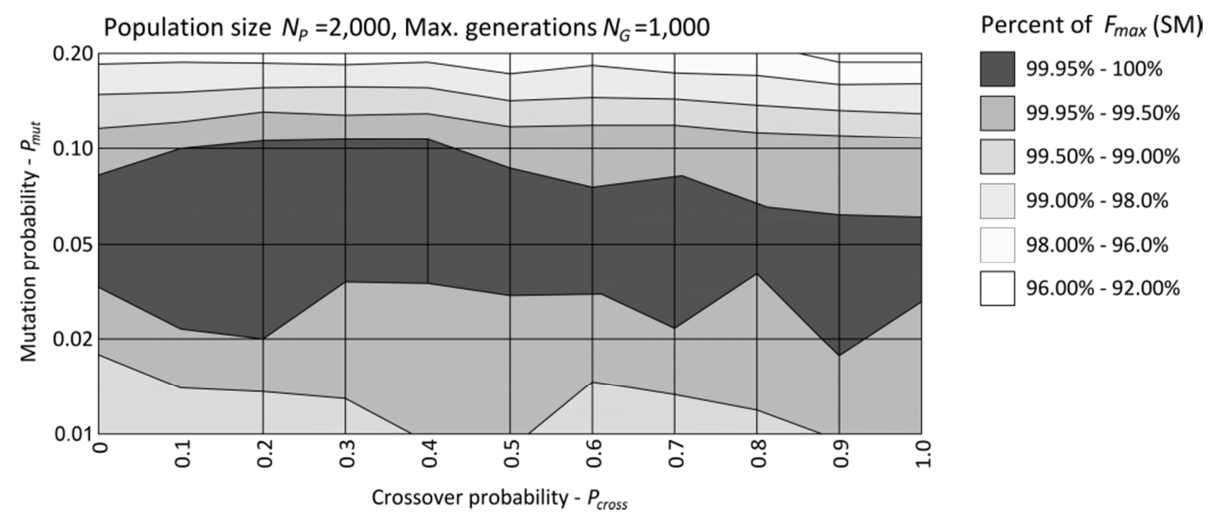

Fig. 7. The effect of $P_{\text {cross }}$ and $P_{m u t}$ on the maximization of the pseudo-fitness function

\section{Conclusions}

The focus of this paper is on the impact of the parameters of GAs on the solution of a hydro-thermal system of 1 hydro power plant and 1 thermal (coal) power plant. Function (1), which describes the problem, was modified and solved in a linear form, so it could be compared with the Simplex method results. The Simplex method was selected for its ability to always find the global extreme of a function (i.e. the best solution). For the above mentioned set of inputs, the impact of the individual GA parameters on 50 simulations was evaluated as follows:

It was proven that satisfactory results can be achieved with a population size of $N_{p}=2000$ and larger in the $1000^{\text {th }}$ generation of a population. More generations will not affect the precision of the solution and only prolongs the simulation time.

The probability parameters $P_{\text {cross }}$ and $P_{m u t}$ have different impacts on the solution. While $P_{\text {mut }}$ has a significant influence, the effect of $P_{\text {cross }}$ was not proven. The sensitivity analysis proved that the best settings for these parameters are converging to the ones recommended by the literature $P_{\text {cross }}=0.75$ and $P_{\text {mul }}=0.05 \sim 0.1$.

\section{Acknowledgement}

This paper was supported by a grant from the Program for the Support of Young Researchers given to the first author in 2015. The program is part of a system to support science and research at the Slovak University of Technology in accordance with recommendations from the European University Association.

This publication is the result of the project implementation: 'Centre of Excellence of Integrated Flood protection of Territory', ITMS 26240120004, supported by the Research \& Development Operational Programme funded by the ERDF. 


\section{References}

[1] Dušička M., Rumann J. Hydropower use of old mills hydraulic scheme in the village of Meliata, Colloquium on Landscape Management 2013, Brno, Czech Republic, Mendel University in Brno, 21 November 2013, pp. 63-68.

[2] Dušička M., Rumann J. The additional energy use of existing water structures, Colloquium on Landscape Management 2014, Proceedings of International PhD Students Conference, Brno, Czech Republic, Mendel University in Brno, 15 November 2014, pp. 63-68.

[3] Tkáč Š., Sečka L., Vranayová Z. Hydro-energy in Slovak republic and Taiwan R.O.C., Pollack Periodica, Vol. 9, No. 3, 2014, pp. 59-70.

[4] Tkáč Š., Vranayová Z. The 'UFO' micro-urban multipurpose turbine, Pollack Periodica, Vol. 7, No. 3, 2012, pp. 15-21.

[5] Goldberg D. E. Genetic algorithms in search optimization and machine learning, New York, Addison-Wesley, 1989.

[6] Gil E., Bustos J., Rudnick H. Short-term hydrothermal generation scheduling model using a genetic algorithm, IEEE Trans Power Syst. Vol. 18, No. 4, 2003, pp. 1256-1264.

[7] Sulek P., Cipovova K. Heuristic optimization methods for hydro plants generation scheduling, in Current events in hydraulic engineering, Gdańsk, Wydawnictwo Politechniki Gdańskiej, Poland, 2011, pp. 266-276.

[8] Zoumas C. E., Bakirtzis A. G., Theocharis J. B., Petridis V. A genetic algorithm solution approach to the hydrothermal coordination problem, IEEE Trans Power Syst, Vol. 19, No. 2, 2004, pp. 1356-1364.

[9] Piraianu V., Vasiliu N., Popa R., Piraianu C. Development of a decision system support based on genetic algorithms for the optimal operation of hydroelectric power plants on the day ahead market, UPB Scientific Bulletin, Series D, Mechanical Engineering, Vol. 77, No. 2, 2015, pp. 247-256.

[10] Li F. F., Shoemaker C. A., Qiu J., Wei J. H. Hierarchical multi-reservoir optimization modeling for real-world complexity with application to the Three Gorges system, Environmental Modeling and Software, Vol. 69, 2015, pp. 319-329.

[11] Akbari-Alashti H., Bazorg Haddad O., Mariño M. A. Application of fixed length genetic programming (FLGGP) in hydropower reservoir operation, Water Resources Management, Vol. 29, No. 9, 2015, pp. 3357-3370.

[12] Li Y. F., Tutu K. A. Overall improved genetic algorithm applied in optimal generation dispatching of multi-reservoir system, Journal of Mechanical Engineering Research and Developments, Vol. 38, No. 2, 2015, pp. 102-106.

[13] Wang J., Huang W., Ma G. Multi-objective optimization of cascade hydropower stations based on improved partheno-genetic algorithm, Journal of Sichuan University (Engineering Science Edition), Vol. 46, SUPPL. 2, 2014, pp. 1-6.

[14] Wu R. N., Lee T. H., Hill E. F. An investigation of the accuracy and the characteristics of the peak-shaving method applied to production cost calculations, IEEE Trans Power Syst, Vol. 4, No. 3, 1989, pp. 1043-1049.

[15] Wu R. N., Lee T. H., Hill E. F. Effect of interchange on short-term hydrothermal scheduling, IEEE Trans Power Syst. Vol. 6, No. 3, 1991, pp. 1217-1223.

[16] Simopoulos D. N., Kavatza S. D., Vournas C. D. An enhanced peak shaving method for short term hydrothermal scheduling, Energy Conversion and Management, Vol. 48, 2007, pp. 3018-3024.

[17] www.neurodimension.com, (last visited 1 December 2015). 